\title{
Author Correction: Genome-enabled discovery of anthraquinone biosynthesis in Senna tora
}

\author{
Sang-Ho Kang (D, Ramesh Prasad Pandey, Chang-Muk Lee, Joon-Soo Sim, Jin-Tae Jeong, Beom-Soon Choi, \\ Myunghee Jung, Daniel Ginzburg (1D, Kangmei Zhao, So Youn Won, Tae-Jin Oh, Yeisoo Yu, Nam-Hoon Kim, \\ Ok Ran Lee, Tae-Ho Lee, Puspalata Bashyal, Tae-Su Kim (D), Woo-Haeng Lee, Charles Hawkins (D), \\ Chang-Kug Kim (D), Jung Sun Kim (D), Byoung Ohg Ahn, Seung Yon Rhee \& \& Jae Kyung Sohng (D)
}

Correction to: Nature Communications https://doi.org/10.1038/s41467-020-19681-1, published online 18 November 2020.

In the original version of this Article, two sentences were incorrectly stated. First, in the last sentence of the second paragraph of the Introduction, "Bacteria, fungi and insects make anthraquinones via a polyketide pathway using complex polyketide synthase enzymes" should read "Bacteria, fungi and insects make anthraquinones via a polyketide pathway using type I or II polyketide synthases". Second, in the second to last paragraph of the Results and discussion section, the sentence "Unlike in plants, anthraquinones are produced via type II PKS enzymes in bacteria such as Streptomyces ${ }^{43-45}$, Photorhabdus luminescens ${ }^{46,47}$ and Verrucosispora" 48 should read "Unlike in plants, anthraquinones are produced via type II PKS enzymes in bacteria such as Streptomyces" ${ }^{43-45}$, Photorhabdus luminescens ${ }^{46,47}$ and Verrucosispora ${ }^{48}$, and type I PKS enzymes in fungi"18,23.

In addition, two Supplementary Data files were incorrectly cited and one Supplementary Data file was omitted to cite in the Results and discussion section. First, in the second paragraph of the section "Metabolite profiling and transcriptomics of seed development" the Supplementary Data file supporting the statement "The majority $(68 \%)$ of genes decreased in expression during seed maturation" was incorrectly cited as Supplementary Data 4. It should be Supplementary Data 9. Second, in the same section and paragraph the Supplementary Data file supporting the statement "Similarly, metabolic gene expression decreased across all metabolic domains during seed maturation (Supplementary Fig. 15)" was omitted to cite. The sentence should read "Similarly, metabolic gene expression decreased across all metabolic domains during seed maturation (Supplementary Fig. 15 and Supplementary Data 4)". Third, in the same section and paragraph the Supplementary Data file supporting the statement "However, some genes increased in expression during seed maturation" was incorrectly cited as Supplementary Data 7. It should be Supplementary Data 9. These have now been corrected in both the PDF and HTML versions of the Article.

Furthermore, the original HTML version of this Article was updated shortly after publication because the previous HTML version linked to an incorrect Source Data file.

Published online: 08 March 2021

\footnotetext{
(c) Open Access This article is licensed under a Creative Commons Attribution 4.0 International License, which permits use, sharing, adaptation, distribution and reproduction in any medium or format, as long as you give appropriate credit to the original author(s) and the source, provide a link to the Creative Commons license, and indicate if changes were made. The images or other third party material in this article are included in the article's Creative Commons license, unless indicated otherwise in a credit line to the material. If material is not included in the article's Creative Commons license and your intended use is not permitted by statutory regulation or exceeds the permitted use, you will need to obtain permission directly from the copyright holder. To view a copy of this license, visit http://creativecommons.org/licenses/by/4.0/.
}

(C) The Author(s) 2021 